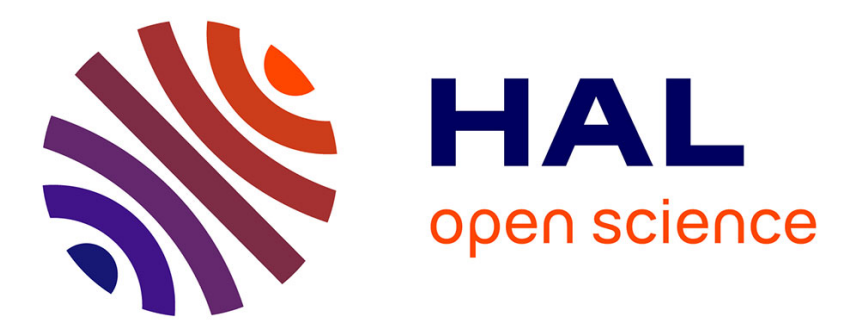

\title{
Comparison of physical and electrical properties of ULPCVD and VLPCVD in situ phosphorus doped polysilicon or undoped polysilicon
}

\author{
M. Sarret, A. Liba, O. Bonnaud, F. Le Bihan, B. Fortin
}

\section{To cite this version:}

M. Sarret, A. Liba, O. Bonnaud, F. Le Bihan, B. Fortin. Comparison of physical and electrical properties of ULPCVD and VLPCVD in situ phosphorus doped polysilicon or undoped polysilicon. Journal de Physique IV Proceedings, 1993, 03 (C3), pp.C3-411-C3-417. 10.1051/jp4:1993357 . jpa00251414

HAL Id: jpa-00251414

https://hal.science/jpa-00251414

Submitted on 1 Jan 1993

HAL is a multi-disciplinary open access archive for the deposit and dissemination of scientific research documents, whether they are published or not. The documents may come from teaching and research institutions in France or abroad, or from public or private research centers.
L'archive ouverte pluridisciplinaire HAL, est destinée au dépôt et à la diffusion de documents scientifiques de niveau recherche, publiés ou non, émanant des établissements d'enseignement et de recherche français ou étrangers, des laboratoires publics ou privés. 


\title{
Comparison of physical and electrical properties of ULPCVD and VLPCVD in situ phosphorus doped polysilicon or undoped polysilicon
}

\author{
M. SARRET, A. LIBA, O. BONNAUD, F. LE BIHAN and B. FORTIN \\ Groupe de Microélectronique et Visualisation, URA 1648 du CNRS, Centre Commun de \\ Microélectronique de l'Ouest, Université de Rennes I, Campus de Beaulieu, 35042 Rennes cedex, France
}

\begin{abstract}
We have analyzed the physical and electrical properties of Ultra Low Pressure Chemical Vapor Deposition (ULPCVD) and Very Low Pressure Chemical Vapor Deposition (VLPCVD) films of polysilicon. The films are either undoped or in-situ phosphorus doped by varying the phosphine/silane gas mole ratio from $4 \times 10^{-6}$ to $4 \times 10^{-4}$. For ULPCVD films, pressure is fixed at $10 \mu \mathrm{bar}$ ( 1 Pascal) whereas for the VLPCVD ones it is fixed at $100 \mu \mathrm{bar}(10$ Pascal). Films are physically and electically characterized. From the analysis of the results it appears that because the deposition rate and the conductivity of ULPCVD films are always lower than the VLPCVD ones, the in-situ phosphorus doped VLPCVD films are potentially better for applications.
\end{abstract}

\section{1. - Introduction.}

Polycrystalline silicon thin films grown by very low pressure chemical vapor deposition (VLPCVD) from decomposition of silane are currently used as polycrystalline gates or emitters in integrated circuits, as well as active semiconductor layers in low temperature process devices such as thin film transistors for active matrix of flat panel displays. In this paper, we give a comparison of structural and electrical properties of polysilicon thin films either undoped or in-situ phosphorus doped and deposited by chemical vapor deposition, on one hand at ultra low pressure,10 $\mu$ bar (ULPCVD) [1], on the other hand, at very low pressure, $100 \mu \mathrm{bar}$ (VLPCVD).

\section{2. - Experimental procedure.}

Undoped or phosphorus doped polysilicon films were deposited onto 7059 Corning glass substrates by thermal decomposition of a mixture of pure silane and phosphine diluted in helium inside a thermal LPCVD reactor. The deposition temperature is fixed at $550^{\circ} \mathrm{C}$ as proposed in previous works [2]; this parameter is measured in experimental conditions with a boat charged with 24 samples. Two deposition pressures have been chosen, 10 microbars (or 1 Pascal) corresponding to the ULPCVD process, and 100 microbars (or 10 Pascal) to the VLPCVD one. These two pressures are monitored by opening a throttle valve while the gas flow of silane is maintained constant at 50 s.c.c.m and the $1 / 00$ diluted phosphine flow is adjusted from 0.2 to 20 s.c.c.m. This gives a phosphine/silane mole ratio controlled in the range $4 \times 10^{-6}$ $-4 \times 10^{-4}$. After deposition, all the films are annealed in a secondary vacuum at $\mathrm{Ta}=600^{\circ} \mathrm{C}$ for 12 hours.

\section{3. - Results.}

We will compare successively the deposition rates, the structural, physical and electrical properties of ULPCVD and VLPCVD films.

A - Deposition rate.

The deposition rate is a function of total deposition pressure and phosphine/silane mole ratio, $\Gamma$, as shown in figure 1. 


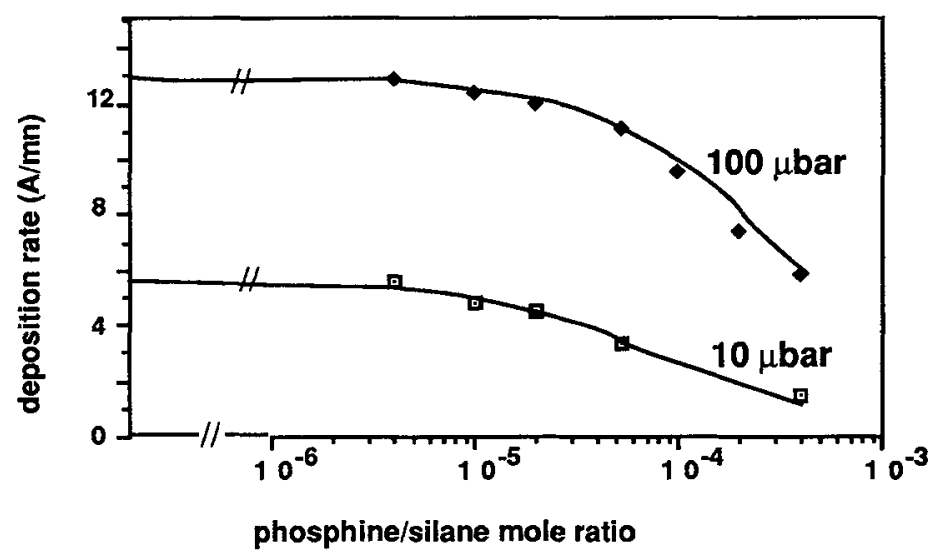

Fig. 1. Deposition rate versus phosphine/silane mole ratio for 10 and $100 \mu$ bar total gas pressures.

The deposition rate is three times higher at a pressure of $100 \mu$ bar than at the $10 \mu$ bar. The deposition rate at $550^{\circ} \mathrm{C}$ is then well described by the following empirical formula [3]:

$$
R(P, \Gamma)=5 \sqrt{\mathrm{P}} *\left[1-\frac{1}{10} \ln (1+\Gamma)\right] \quad(\AA / \mathrm{min})
$$

where the pressure, $P$, is expressed in Pascal (in the range 1 to 10 ) and $\Gamma=10^{6} \times \Gamma$ experimental ;

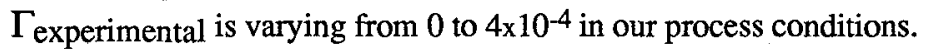

B- Structural properties.

Structural properties were examined from X-ray diffraction analysis and Transmission Electron Microscopy (TEM). X-ray diffraction in $\theta-2 \theta$ mode allows the determination of the orientation factor $\mathrm{O}_{\mathrm{hkl}}$ shown in tables 1 and 2 and the crystallite size $\mathrm{S}_{\mathrm{hkl}}$ as reported table 3 . TEM allows the determination of the average grain size (table 4 ) and grain shape [4] as shown in figure 2.

\begin{tabular}{|c|c|c|c|c|c|}
\hline $\mathrm{PH}_{3} / \mathrm{SiH}_{4}$ & 0 & $4 \times 10^{-6}$ & $10^{-5}$ & $4 \times 10^{-5}$ & $10^{-4}$ \\
\hline $\mathrm{e}(\mathrm{A})$ & 4000 & 4000 & 4000 & 4000 & 4000 \\
\hline $\mathrm{O}_{111}$ & $37 \%$ & $40 \%$ & $38 \%$ & $37 \%$ & $34 \%$ \\
\hline $\mathrm{O}_{220}$ & $16 \%$ & $16 \%$ & $20 \%$ & $23 \%$ & $28 \%$ \\
\hline $\mathrm{O}_{311}$ & $47 \%$ & $44 \%$ & $42 \%$ & $40 \%$ & $38 \%$ \\
\hline
\end{tabular}

Table 1 : Orientation factors measured by $\mathrm{X}$-ray diffraction on poly-Si films deposited at variouss $\mathrm{PH}_{3} /$ $\mathrm{SiH}_{4}$ mole ratio and $100 \mu$ bar total gas pressure (VLPCVD); orientation factor, $O_{\text {hkl }}$, thickness, $e$.

Table 1 gathers results of VLPCVD films and shows that only diffraction peaks $\langle 111\rangle,\langle 220\rangle$, and $<311>$ can be observed; it also shows that the orientation factor is slightly dependent on the phosphine /silane mole ratio. No preferential orientation is detected in the polycrystalline structure. 


\begin{tabular}{|c|c|c|c|c|}
\hline $\mathrm{PH}_{3} / \mathrm{SiH}_{4}$ & 0 & $4 \times 10^{-6}$ & $4 \times 10^{-5}$ & $4 \times 10^{-4}$ \\
\hline $\mathrm{e}(\mathrm{A})$ & 2000 & 2600 & 2050 & 1000 \\
\hline $\mathrm{O}_{111}$ & $0 \%$ & $0 \%$ & $0 \%$ & $0 \%$ \\
\hline $\mathrm{O}_{220}$ & LS & $100 \%$ & LS & LS \\
\hline $\mathrm{O}_{311}$ & $\mathrm{NS}$ & $0 \%$ & $\mathrm{NS}$ & $\mathrm{NS}$ \\
\hline
\end{tabular}

Table 2: Orientation factors measured by X-ray diffraction on poly-Si films deposited at different $\mathrm{PH}_{3} / \mathrm{SiH}_{4}$ mole ratio and $10 \mu$ bar total gas pressure (ULPCVD); low signal $L S$, no signal, $N S$.

Table 2 concerns ULPCVD layers ( $10 \mu$ bar) and shows a disappearence of the $\langle 111\rangle$ diffraction peak for the undoped films as well as for the doped one. In this table, NS means no signal, that is to say the corresponding signal is not observed; LS, means low signal, that is to say the signal exists but is not measured with enough accuracy; $\mathrm{O} \%$ means that the corresponding peak does not exist. Films having a thickness of $2600 \AA$ (corresponding to phosphine/silane mole ratio of $4 \times 10^{-6}$ ) give only one diffraction peak in the $<220>$ direction .

\begin{tabular}{|c|c|c|c|c|c|}
\hline $\mathrm{PH}_{3} / \mathrm{SiH}_{4}$ & 0 & $4 \times 10^{-6}$ & $10^{-5}$ & $4 \times 10^{-5}$ & $10^{-4}$ \\
\hline $\mathrm{S}_{111}(\AA)$ & 935 & 700 & 750 & 960 & 830 \\
\hline $\mathrm{S}_{220}(\AA)$ & 847 & 849 & 780 & 756 & 860 \\
\hline $\mathrm{S}_{311}(\AA)$ & 550 & 897 & 850 & 760 & 800 \\
\hline
\end{tabular}

Table 3. Crystallite sizes measured by X-ray diffraction on a $4000 \AA$ thick poly-Si films deposited at a pressure of $100 \mu \mathrm{bar}$.

The average crystallite sizes are given in Table 3 . The average crystallite size of VLPCVD film is nearly independent of phosphine/silane mole ratio, and is approximately $800 \AA \tilde{A}$. For ULPCVD films the size is $500 \AA$ in the $<220>$ direction, and then lower than the VLPCVD one.

\begin{tabular}{|c|c|c|c|}
\hline$\Gamma$ & $4 \times 10^{-6}$ & $10^{-5}$ & $4 \times 10^{-4}$ \\
\hline $\mathrm{e}(\AA)$ & 4000 & 4000 & 4000 \\
\hline $\mathrm{L}(\AA)$ & 3250 & 3200 & 3100 \\
\hline
\end{tabular}

Table 4 : Lateral grain sizes, L $(\AA)$ obtained by TEM on $4000 \AA$ thick silicon films deposited at $100 \mu$ bar.

Table 4 shows an average grain size for VLPCVD films independent of the phosphine/silane mole ratio and close to the film thickness $(e=4000 \AA)$. Figure 2 shows from TEM measurements a dendritic morphology for films prepared at $100 \mu$ bar. 


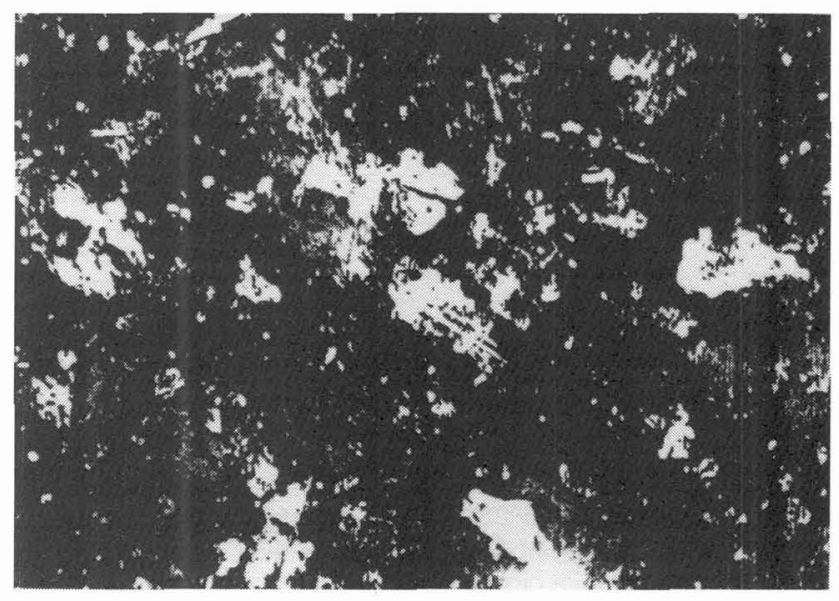

Fig. 2. - Transmission Electron Micrograph of $4000 \AA$ thick silicon film deposited on glass substrate at $100 \mu$ bar total gas pressure.

C- Physical and electrical properties.

Figure 3 shows the variation of incorporated phosphorus atom concentration deduced from SIMS measurements as a function of the phosphine/silane mole ratio with the total deposition pressure as a parameter.

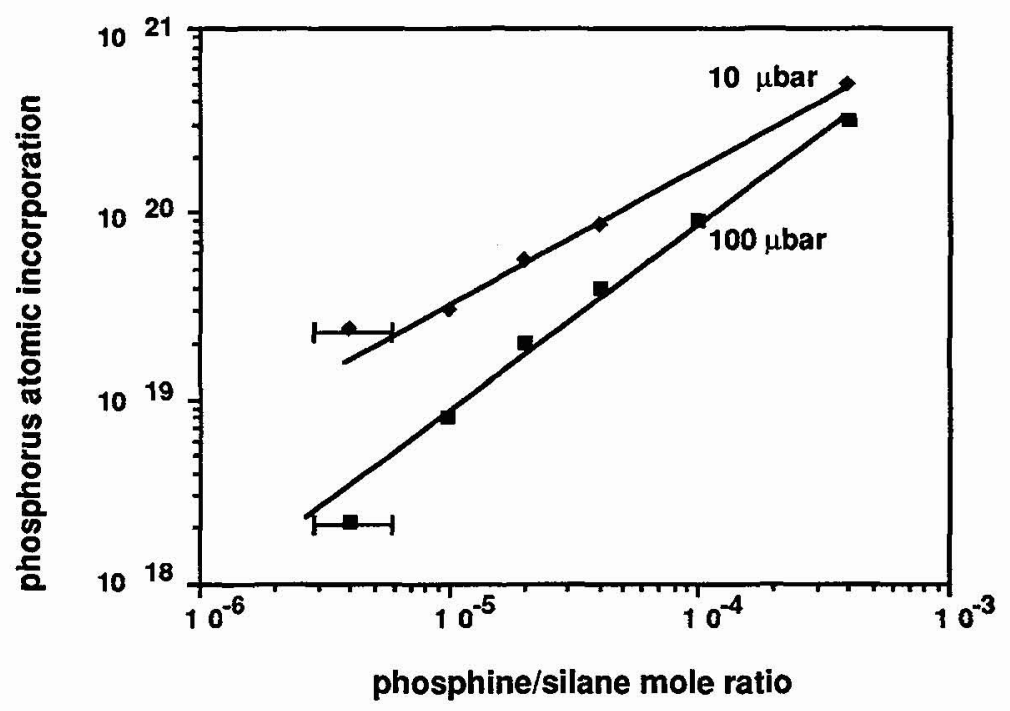

Fig. 3. Phosphorus concentration versus phosphine/silane mole ratio for $100 \mu$ bar and $10 \mu$ bar total gas pressure; variation is linear in the log-log plot. 
Linear variations of phosphorus atom concentration with gas mole ratio can be observed in the $\log -\log$ plot. This figure also shows that for all the mole ratio the phosphorus atom incorporation is higher for ULPCVD films than VLPCVD ones. Figure 4 shows the resistivity of polysilicon films deduced from four probe measurements with phosphine/silane mole ratio as a parameter for the two deposition pressures.

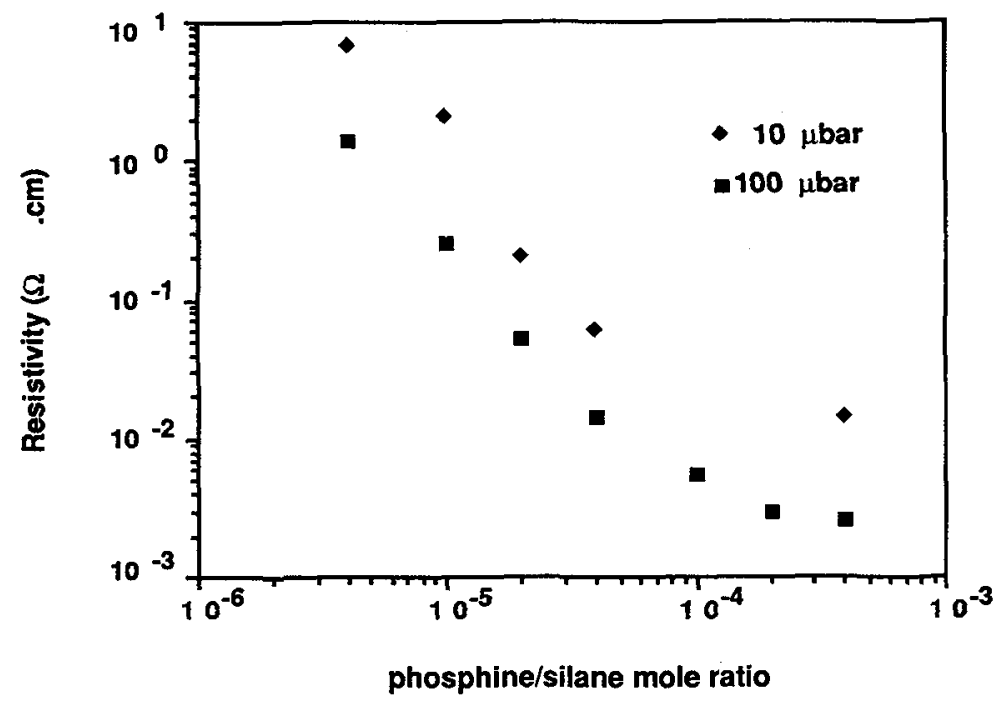

Fig.4. Resistivity versus phosphine /silane mole ratio for $100 \mu \mathrm{bar}$ and $10 \mathrm{bar}$ total gas pressure.

One can observe that the ULPCVD films are more resistive than the VLPCVD ones; their values is 5 to 10 higher in the whole range of $\Gamma$. This observation appears in contradiction with the variation of the phosphorus atom incorporation shown figure 3. The gap between the resistivities is evident in figure 5 where the resistivity is plotted as a function of the phosphorus atom incorporation.

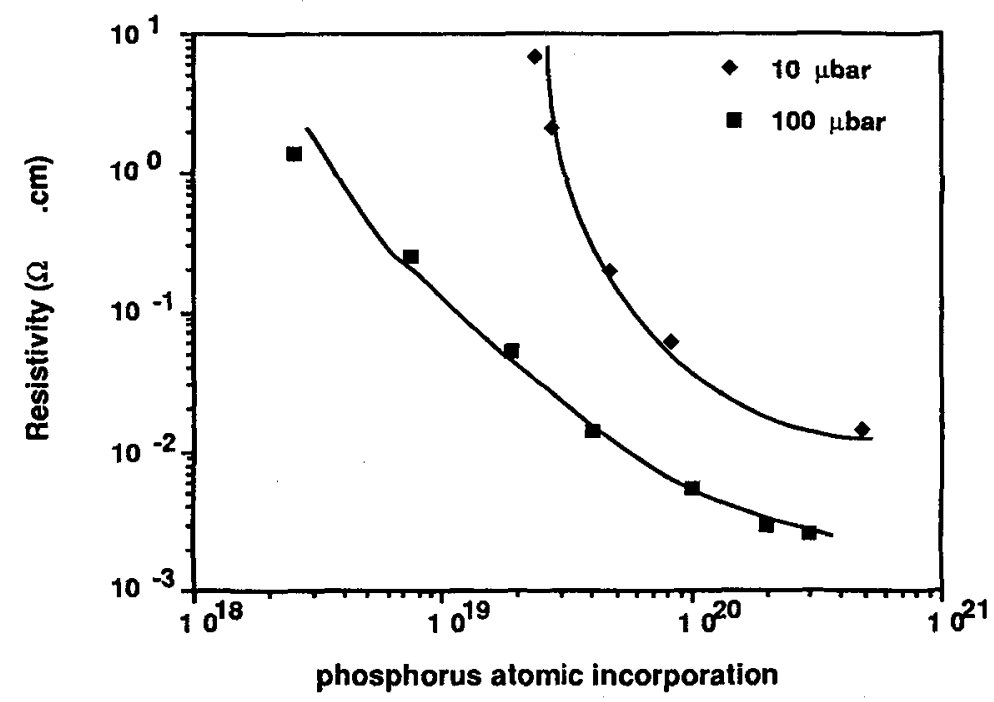

Fig. 5. Resistivity versus phosphorus atomic incorporation concentration (cp) with pressure as a parameter. 
To solve this apparent contradiction we have performed Hall effect measurements at $20^{\circ} \mathrm{C}$ from which we have calculated the active phosphorus doping concentration [5]. Figure 6 shows the variation of the doping efficiency, defined as the phosphorus atom incorporation/active phosphorus concentration ratio as a function of phosphine/silane mole ratio. We may observe that the doping efficiency is in about 5 times higher for the VLPCVD films than for ULPCVD ones. This means that the higher resisitvity of the ULPCVD films is linked to the low doping efficiency of these films.

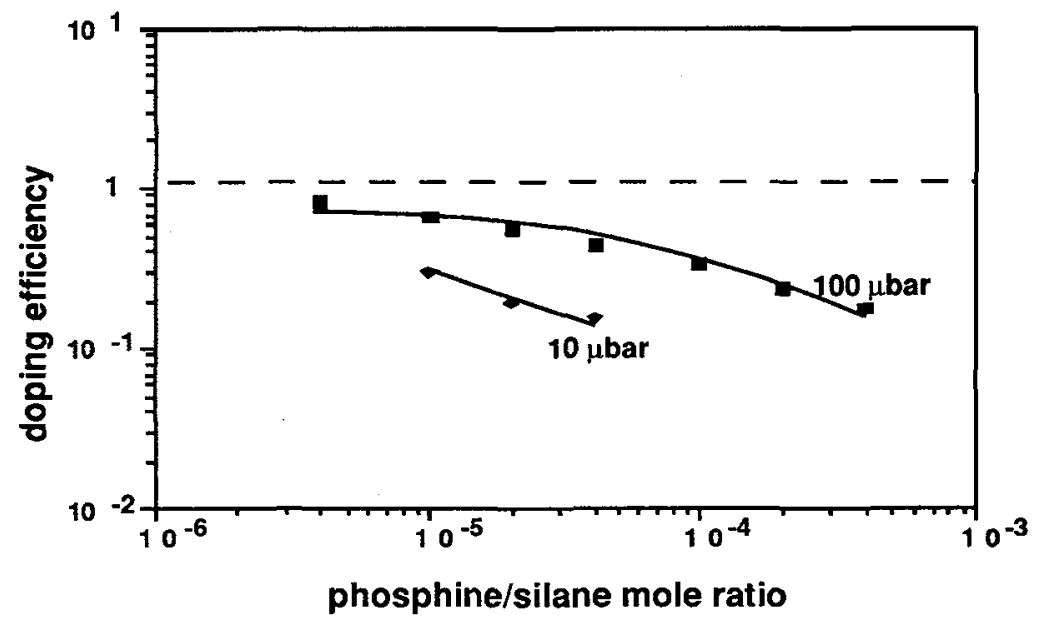

Fig.6. Phosphorus doping efficiency versus phosphine/silane mole ratio for films deposited at $100 \mu$ bar and $10 \mu$ bar total pressure.

Indeed, figure 7 shows that the resistivity of ULPCVD and VLPCVD films depends only on the active doping concentration, the crystallite size having no significant influence on the active doping concentration. Raman analysis shows, for example, that crystallite size has no influence on the resistivity.

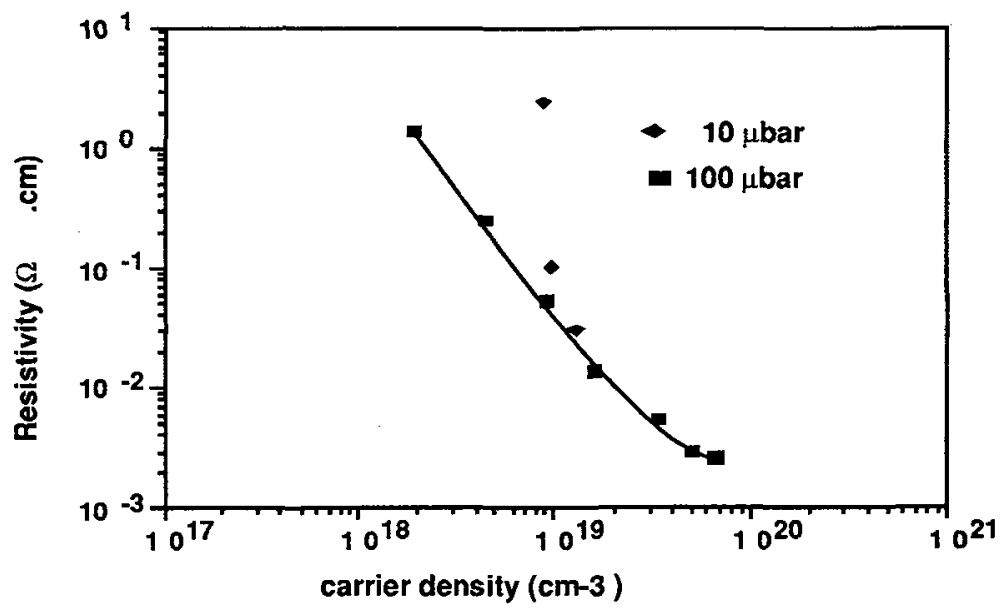

Fig. 7. Resistivity versus free carrier concentration deduced from Hall effect measurement, for films deposited at $100 \mu \mathrm{bar}$ and $10 \mu \mathrm{bar}$ total gas pressure. 


\section{4. - Discussion}

From the results mentioned-above, we have observed that the resistivity is linked to the doping efficiency and that this efficiency appears to be dependent on the deposition pressure. This can be explained by the fact that the polysilicon ULPCVD films deposited at $10 \mu$ bar are "as-deposited", that is to say, crystallized during the growth of the film before any thermal annealing, while the VLPCVD films deposited at 100 $\mu$ bar are amorphous during the growth and crystallized during the thermal annealing [6]; this difference has been checked from Raman analysis of the films. Then, the incorporation efficiency mainly depends on the morphology of the film during the growth. Thus, when the crystallization phase occurs during the growth morphology and electrical properties of the final layer are fixed and the end of the growth, while when the deposited layer is amorphous, morphology and electrical properties are determined during the crystallization phase. The best results are obtained when the crystallization occurs during the thermal annealing.

\section{5. - Conclusion}

The ULPCVD films deposited at $10 \mu \mathrm{bar}$ have a too large resistivity and a too low deposition rate to have a potential interest for many applications. By contrast, VLPCVD films deposited at $100 \mu$ bar have a surprisingly low resisitivity for a low phosphine/silane mole ratio and the rather low maximum process temperature $\left(\mathrm{T}_{\max }=600^{\circ} \mathrm{C}\right)$; their resistivity as a function of the doping concentration follows with a shift of one decade only the monocrystalline silicon one. This difference between ULPCVD and VLPCVD can be explained by the difference of the growth, the first one being as-deposited, the second one, amorphous deposited and crystallized during the thermal annealing. These VLPCVD films appear as good candidates for applications, especially for fabricating thin film transistors (TFTs) for active matrices of flat panel displays [7].

Aknowledgement. The authors are indebted to M. Gauneau with CNET Lannion B for the SIMS characterizations and to L. Haji, with our group, for TEM analysis. They also wish to thank B. Loisel, N. Duhamel with CNET Lannion B, and Professor J. Stoemenos with University of Thessaloniki (Greece) for helpful discussions.

\section{References}

[1] MEAKIN , J. Physique, colloque C2, vol.1, (1991) C2-8.

[2] SARRET M., LIBA A., BONNAUD O., MOKHTARI M., FOR'TIN B., J. Physique, colloque C2,

[3] LIBA A., Thesis of University of Rennes $I, n^{\circ} 923,(1993)$

vol.1, (1991) C2-817-822.

[4] STOEMENOS J., ECONOMOU N.A., Poly-Si Devices and Applications Conf., London (UK), (1993) 21.1.

[5] MANDURAH M.M., SARASWAT K.C. and KAMINS T.I., Phosphorus doping of low pressure chemically vapor-deposited silicon films, J. Electrochem. Soc., SSST,.vol.126 (6), 1979.

[6] HARBEKE G., KRAUSBAUER L., STEIGMEIER E.F. and WIDNER A.E., High quality polysilicon by amorphous low pressure chemical vapor deposition, Appl. Phys. Lett., 42 (3), 1983.

[7] SARRET M., LIBA A., FORTIN B., LE BIHAN F., PICHON L., BONNAUD O., Poly-Si Devices and Applications Conf., London (UK), (1993) 10.1. 